\title{
An International Study on Dietary Supplementation Use in Dancers
}

\author{
Derrick Brown, MSc, and Matthew Wyon, PhD
}

Little is known of the prevalence and motives of dietary supplement use amongst dancers from different cultures. Investigating supplement use, presumed effects, and other factors may be crucial for improving educational and nutritional advice provided for this cohort. Therefore, this study investigated the use of dietary supplements in 334 dancers from 53 countries, who completed a digitally based 35-question survey detailing demographic information and the use of dietary supplementation. Supplement use was prevalent amongst this international cohort, with $48 \%$ reporting regular supplement use. Major motives for supplement use were to improve health, boost immunity, and reduce fatigue. Forty-five percent believed that dancing increased the need for supplementation, whilst 30\% recognized that there were risks associated with nutritional supplementation. The most frequently consumed supplements were vitamin C (60\%), multivitamins (67\%), and caffeine (72\%). A smaller group of participants declared the use of whey protein $(21 \%)$ or creatine (14\%). Supplements were mainly obtained from pharmacies, supermarkets, and health-food stores. Dancers recognized their lack of knowledge in dietary supplement use and relied on peer recommendations instead of sound evidence-based advice from acknowledged nutrition or health care professionals. This study demonstrates that dietary supplement use is internationally prevalent amongst dancers. Continued efforts are warranted with regard to information dissemination. Med Probl Perform Art 2014; 29(4):229-234.

I

n the United States, the Food and Drug Administration regulates both finished dietary supplements and dietary ingredients. The 1994 Dietary Supplement Health and Education Act defined a dietary supplement as an orally consumed product intended to supplement one's diet. ${ }^{1}$ This includes vitamins, minerals, herbs or botanicals, amino acids, enzymes, organ tissues, metabolites, extracts, or concentrates in the form of tablets, capsules, liquids, powders, bars, soft gels, or gel caps. ${ }^{1}$ The European Union uses the term food supplements as concentrated sources other than vitamins, minerals, and/or other substances (such as amino acids, essential fatty acids, fiber, and vari-

$\mathrm{Mr}$. Brown is Associate Researcher at ArtEZ Institute of Arts and the National Centre for Performing Arts, Arnhem, the Netherlands; and Dr. Wyon is Research Professor at the Research Centre for Sport Exercise and Performance, University of Wolverhampton, Walsall, and National Institute of Dance Medicine and Science, UK.

Presented in part at the 22nd International Association of Dance Medicine $\mathcal{E}$ Science Symposium, Singapore, Oct 2012.

Address correspondence to: $\mathrm{Mr}$. Brown, ArtEZ Institute of the Arts, Onderlangs 9, 6812 CE Arnhem, the Netherlands. Tel +31655358027. De.Brown@artez.nl.

(C) 2014 Science $\mathcal{E}$ Medicine. www.sciandmed.com/mppa. ous plant and herbal extracts) sold as pills, tablets, and other dose forms. ${ }^{2}$ Given these discrepancies in terminology, the generic term dietary supplement (DS) is used here to denote all of the above descriptions.

Dietary supplement use is common in the general population: National Health and Nutrition Examination Survey (NHANES) data collected from 2003 to 2006 indicated that $53 \%$ of American adults took at least one dietary supplement, most commonly multivitamin/multimineral supplements. ${ }^{3}$ In the United Kingdom, the Food and Standards Agency reported that $30 \%$ of adults took vitamins, minerals, or DS on most days. Researchers here noted that while the definition of a high-strength vitamin and mineral supplement is not straight forward, 15\% of consumers reported taking a "high dose" supplement in the last 12 months period. ${ }^{4}$ In sport science, it is well documented that high-performance athletes use DS for not only health and wellbeing, but also performance enhancement. ${ }^{5,6}$ Moreover, previous studies have reported a prevalence of DS between 46 and $91 \%$ in adolescent and young athletes as well, from vitamins and minerals, to sport beverages and fatty acids. ${ }^{7-9}$

Several studies have highlighted DS use in dancers. Stensland and Sobel ${ }^{6}$ surveyed 106 ballet, jazz, and modern dancers and revealed $60 \%$ used a vitamin and mineral supplement. In a study assessing the effects of nutrition, puberty, and dancing on bone density in adolescent ballet students, Burckhardt et al. ${ }^{10}$ reported that $57 \%$ $(n=72 / 127)$ took multimineral supplements, vitamins, or both while only $13 \%$ reported ingesting calcium supplements. Finally, in the largest study done in dance, the 2002 Fit to Dance 2 survey ( $n=1056)$, 63\% took supplements, 56\% vitamins, 20\% iron, 20\% calcium, and 16\% stated other. ${ }^{11}$

It is clear from the studies cited that dancers do consume DS. However, these studies report only on vitamin and minerals supplements and not the comprehensive assortment currently available in the market. Investigating DS use within dancers, the reasons for it, and other factors is crucial for the improvement of educational and nutritional advice provided for this cohort. Thus, the purpose of this study was to investigate the use of DS in an international cohort of dancers.

\section{METHODS}

\section{Participants}

Selection criteria required that participants be 17 years old plus and dance on average $20 \mathrm{hrs}$ / week for the past 3 years. Participants were asked to indicate whether they were in full-time training (defined as pre-professional) or profes- 
sional dancers (defined as 6-to 12-month dance contract in the last year). A sample of 411 participants ( 256 females, 74 males, age range 17-69 yrs) started the survey, with 334 completing all questions for a response rate of $81 \%$.

The objectives and requirements of the study were explained and consent was obtained from all respondents. This study was reviewed and approved by a University of Wolverhampton Faculty Ethics Review Board.

To test for English language comprehension, a draft version of the survey was circulated to 12 non-native Englishspeaking individuals before distribution of the questionnaire commenced. Their answers were not included in the statistical analysis. Several distribution channels were utilized in order to recruit participants, including email communication with dance company teachers and rehearsal directors, dance schools, university dance department administrators, virtual online networks, as well as dance-specific Internet websites. All questionnaires were filled-in online via an SSL IPaddress-secure survey system (Appendix 1).*

\section{Questionnaire}

The survey consisted of 35 questions that collected data on type of dance education, professional status, type of dance genre, current years in education or as a professional dancer, the variety and frequency of DS used, and reasons for supplementation. A certified athletic trainer, an exercise physiologist, a certified sports nutritionist who specializes in nutrition for dancers, and two dance educators reviewed the questionnaire for inconsistencies. Table 1 shows the breakdown of the dancers by level and genre of dance study.

Questions focused on participants' DS use from a variety of categories. One single definition for "supplement" was not defined in the questionnaire. As mentioned in the previous section, given the diversity within this sample, the difference in cultural representation and delineations of the term supplement in different countries, it was decided to use the generic term dietary supplementation. In the data analyses, however, supplements were divided into subgroups. These categories were devised as described by Huang et al., ${ }^{12}$ and we utilized the supplements listed in the British Journal of Sport Medicine 36-part review on supplementation. ${ }^{13}$ Key questions assessed supplement use from micronutrient (e.g., vitamins and minerals), ergogenic (e.g., caffeine, energy drinks), weight control (e.g., protein powder, weight gain powders), and supplements categorized as performance enhancing (e.g., creatine, branched chain amino acids). Open-ended questions concerning respondents experience with supplementation were also utilized.

To categorize answers regarding perceptions of DS usage, participants were asked to rate DS use via four categories: DS is associated with health risks, DS enhances performance, dancing increases the need for DS, and DS are not needed with a balanced diet. These were specific,

\footnotetext{
*Appendix 1 appears in the online version of this paper, available at
} www.sciandmed.com/mppa (see December 2014 issue, vol 29, no 4).
TABLE 1. Dance Profession or Educational Status $(n=280)$

\begin{tabular}{lcc}
\hline Category & $\begin{array}{c}\text { No. of } \\
\text { Respondents }\end{array}$ & $\begin{array}{c}\% \text { of } \\
\text { Respondents }\end{array}$ \\
\hline $\begin{array}{l}\text { Pre-professional student/university } \\
\text { Pre-professional student/academy }\end{array}$ & 11 & 34 \\
$\quad$ or conservatory & 53 & 17 \\
Recreational dance student & 48 & 16 \\
Professional dancer classical & 45 & 15 \\
Professional dancer contemporary & 61 & 20 \\
Professional dancer hip-hop/urban/ & & \\
$\quad$ street & 2 & 1 \\
Professional dancer style/ballroom & 2 & 1 \\
Professional dancer world dance & 3 & 1 \\
Dancing/performing choreographer & 33 & 11 \\
Dancer/entertainer & 4 & 1 \\
Dance teacher & 18 & 6 \\
\hline
\end{tabular}

independent questions following the entire section on DS. Three 5-point Likert scales were utilized in two question sets. The first set indicated the following numerical and text anchors: $1=$ totally agree, $2=$ somewhat agree, $3=$ unsure, $4=$ disagree, and $5=$ totally disagree. The second set contained the following numerical and text anchors: 1 $=$ extremely healthy, 2 = very healthy, $3=$ moderately healthy, $4=$ slightly healthy, and $5=$ not at all healthy. Finally, the third set contained the following numerical and text anchors: $1=$ extremely knowledgeable, $2=$ very knowledgeable, 3 = moderately knowledgeable, $4=$ slightly knowledgeable, and $5=$ not at all knowledgeable. Table 2 shows the breakdown of dancer use of all possible DS.

\section{Statistical Analysis}

Statistical analysis was performed with SPSS version 19 (IBM-SPSS, Armonk, NY, USA). Analyses were calculated for all participants, age groups, dance categories, and both genders separately. Associations between age, gender, dance group, motives, and supplement use were assessed by chisquare $\left(\chi^{2}\right)$ test. Associations and differences were considered statistically significant if the probability of error was $<0.05$. Initially, we delineated our cohort into categories of professional status as mentioned above. However, there was no statistical difference between professional and pre-professional dancers, and therefore the categories were combined to increase statistical power. All data are presented as frequency (in \%) or as mean and standard deviation $(\mathrm{M} \pm \mathrm{SD}$ ).

\section{RESULTS}

\section{Reported Prevalence and Frequency of Supplement Use}

When asked about general DS intake, $50.2 \%(n=152)$ chose the option no/never, followed by $49.8 \%(n=150)$ answering yes to consuming supplement ingestion on a regular basis. A detailed distribution of nutritional supplements ingested can be seen in Table 3 . 
TABLE 2. Distribution of Supplements Used ( $n=154)$

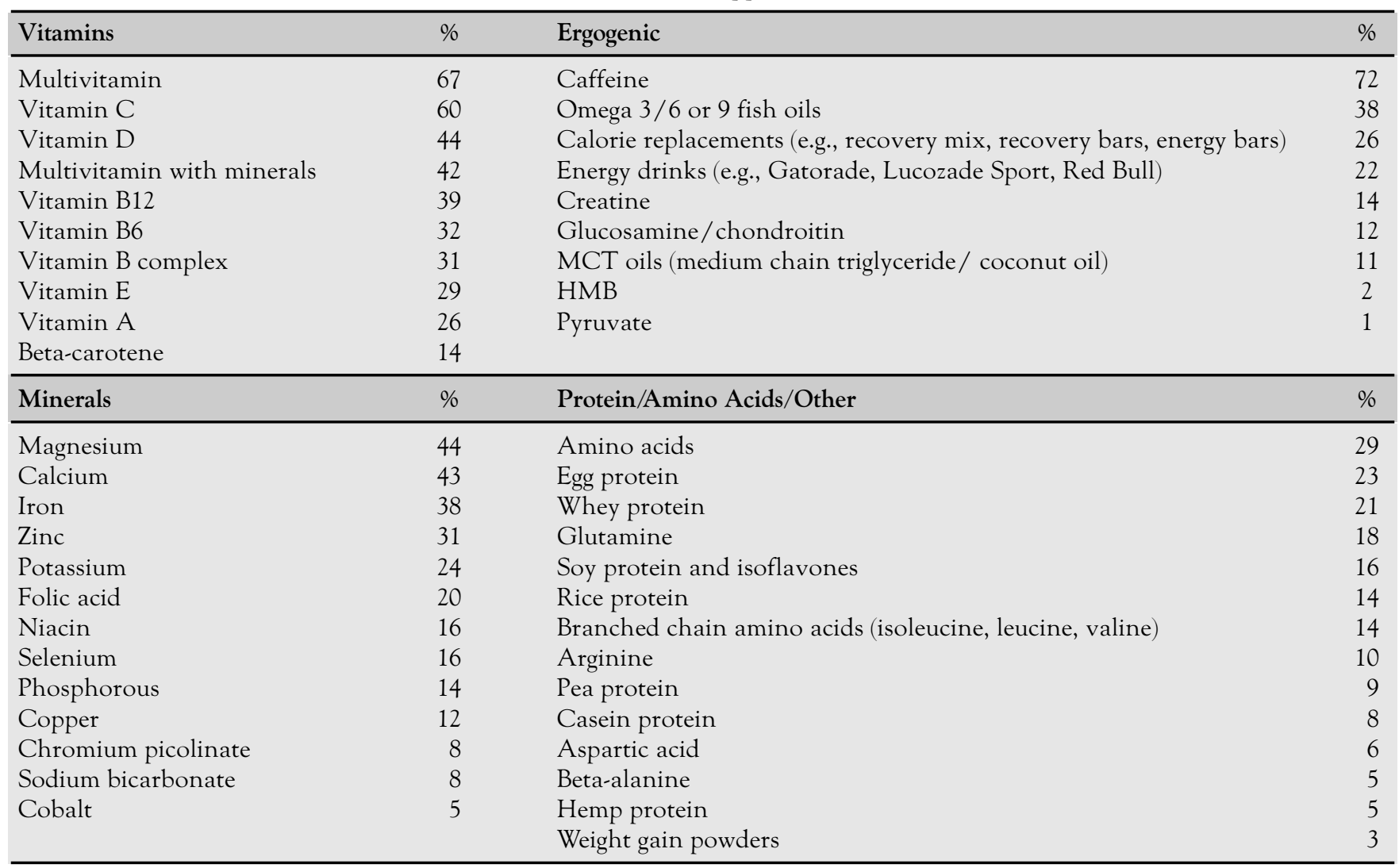

\section{Reason for Supplement Use}

Among the respondents who supplemented, 80\% stated that they did so to "maintain good health," while 56\% did so to "boost immunity," $51 \%$ to "reduce fatigue," $49 \%$ to "improve energy," and 44\% to "prevent injury or illness." Performance-related reasons given were "to improve performance" (36\%), "to speed up recovery after injury" (27\%), and for an "inadequate diet" (20\%). Table 3 extends these questions to country or region.

For associations, we cross-tabulated our respondents who answered yes or no to DS with the query if DS enhanced performance. Chi-square analysis indicated a significant association $\left(\chi^{2}[4, n=45]=52.6, p<0.01\right)$ for those taking supplements; $5 \%$ totally agreed, $18 \%$ somewhat, $7 \%$ were unsure, and $3 \%$ disagreed somewhat that DS enhanced performance. For respondents who did not supplement, $2 \%$ totally disagreed, $21 \%$ somewhat disagreed, $28 \%$ were unsure, $13 \%$ disagreed somewhat, and $6 \%$ disagreed that DS enhanced performance.

\section{Knowledge of Supplements}

We asked questions that ascertained adherence to label instructions and warnings. Fifty-seven percent of 179 respondents (all who answered this specific question) reported following the labels moderately well when ingesting DS, $46 \%$ reported they followed recommendations on the labels very well, while $21 \%$ did so well. A major factor in the decision to use supplements was the influence of friends (68\%), with price (38\%) being a secondary decision after deciding on DS ingestion.

\section{DISCUSSION}

\section{Prevalence of Supplement Use}

A key aim of the current research was to report on DS in dancers globally. Previous surveys ${ }^{11,14}$ have targeted respondents from a single country, while the present study recruited respondents from 53 countries. DS use was prevalent amongst pre- and professional dancers, with 49 $\%$ taking some kind of supplement. This is lower than the $60 \%$ and $78 \%$ reported in previous studies. ${ }^{11,14}$ However, these studies report predominantly on vitamin and mineral combinations and not the comprehensive list presented here. When comparing questions regarding only vitamin and mineral supplementation, the current cohort reported between 60 and $65 \%$ usage.

The most popular ergogenic supplement taken by our female participants was caffeine (73\%). This in contrast to 91\% reported in earlier studies. ${ }^{14}$ There are several reputed ergogenic effects of moderate caffeine consumption: improvements in physical endurance, power output, cognitive function, and decreased perceptions of fatigue. ${ }^{15,16}$ However, high caffeine consumption is not without 
TABLE 3. Percentage of Responses for Questions Regarding the Motivation for Dietary Supplementation, by Geographic Region

\begin{tabular}{lcccccc}
\hline & $\begin{array}{c}\text { Europe } \\
(\boldsymbol{n}=\mathbf{2 0 1})\end{array}$ & $\begin{array}{c}\text { Asia } \\
(\boldsymbol{n}=\mathbf{2 0})\end{array}$ & $\begin{array}{c}\text { Australasia } \\
(\boldsymbol{n}=\mathbf{5})\end{array}$ & $\begin{array}{c}\text { USA/Canada } \\
(\boldsymbol{n}=\mathbf{7 0})\end{array}$ & $\begin{array}{c}\text { South America } \\
(\boldsymbol{n}=\mathbf{2})\end{array}$ & $\begin{array}{c}\text { Africa } \\
(\boldsymbol{n}=\mathbf{3})\end{array}$ \\
\hline Use DS & 41 & 75 & 33 & 71 & 50 & 100 \\
Health & 40 & 100 & 75 & 100 & 50 & 100 \\
Daily routine & 11 & 19 & - & 22 & - & - \\
Immunity & 27 & 62 & 83 & 78 & 50 & 50 \\
Energy & 30 & 38 & 66 & 46 & 100 & 100 \\
Performance & 19 & 38 & 75 & 34 & 50 & 100 \\
Reduce fatigue & 27 & 57 & 25 & 50 & 50 & 100 \\
Poor diet & 10 & 31 & 33 & 22 & 100 & - \\
Improve speed & 3 & 6 & 50 & 6 & - & - \\
Improve strength & 12 & 25 & 50 & 10 & - & - \\
Muscle gain & 6 & 6 & 33 & 4 & - & - \\
Improve endurance & 11 & 19 & 50 & 10 & - & 50 \\
Injury recovery & 17 & 13 & 50 & 10 & - & - \\
Weight loss & 6 & - & 50 & 14 & 100 & 50 \\
Feel better & 12 & 19 & 33 & 30 & 50 & - \\
Increase energy & 15 & 50 & 75 & 34 & 50 & 50 \\
Prevent injuries & 100 & 56 & 50 & 44 & 50 & - \\
Cope with pain & 5 & 13 & 33 & 4 & - & - \\
Concentration & 7 & 25 & 75 & 18 & 50 & - \\
\hline
\end{tabular}

adverse effects, including flushing, tachycardia, and increased urinary excretion of micronutrient concentrations. ${ }^{17,18}$ In addition, caffeine is a known diuretic and could cause problems in many performance-related endeavors; however, this effect appears to be dose-, frequency-, and time-dependent, possibly due to decreased urinary excretion during intense physical performance. ${ }^{19,20}$ The use of caffeine might be explained by the finding that many female dancers use caffeine for its purported weight loss effects, ${ }^{21}$ although this has only been seen efficacious in overweight to moderately obese subjects. ${ }^{22}$

With regard to additional ergogenic supplements, such as branched chain amino acids (BCAAs), creatine, $\beta$-alanine, and $\beta$-hydroxy- $\beta$-methylbutyrate (HMB), $56 \%$ of our respondents answered no to ingesting these supplements, in stark contrast with studies assessing endurance athletes' knowledge and use of ergogenic aids..$^{23,24}$ Of note was the use of aspartic acid and sodium bicarbonate, 5\% and $8 \%$, respectively. Aspartic acid is a non-essential amino acid (i.e., manufactured by the body). Aspartic acid is believed to diminish symptoms of fatigue, although when measured in vivo, the results are not conclusive. ${ }^{25}$ Sodium bicarbonate $\left(\mathrm{NaHCO}_{3}\right)$ has been purported as an ergogenic aid for inducing metabolic alkalosis in contracting musculature. However, meta-analyses have shown this effect to be dependent on dosage and duration of event, ${ }^{26,27}$ with little association to the demands of dance training and performance. ${ }^{28}$

\section{Type and Reason for Supplement Use}

While comparisons of male and female dancers were not part of this study's focus, some observations of differences proved noteworthy. The prevalence for multivitamin use was higher for females (72\%) than males $(28 \%)(p=0.03)$. This is in contrast to observations in other dance cohorts where males (65\%) ingested more multivitamin supplements than females (59\%). ${ }^{14}$ One possible explanation is that females are more aware of dietary inadequacies and thus the need for supplementation. Age, dance profession, and educational status variables did not influence prevalence.

Remarkably, only $30 \%$ of females took daily calcium supplements. It was expected that the continued disseminated message by medical, dietetic, and dance science communities regarding the importance of calcium, in particular for female bone health, would have caused an increase usage. This study as well as earlier ${ }^{29}$ and more recent stud${ }^{i e s^{10}}$ reveal this trend has not yet been reversed.

Similarly, supplemental intake of vitamin D and iron among female participants was low $31 \%$ and $22 \%$, respectively), although research has shown that dancers are often deficient in these micronutrients. ${ }^{30,31}$ Unexpectedly three males reported taking iron supplements on a daily basis. Iron supplementation is unlikely to be required by healthy men ${ }^{32}$ and if taken excessively can have negative health consequences. Common side effects might include diarrhea (may contain blood), fever, and nausea. More serious side effects could include risk of gene mutation as well as camouflaging the presentation of factors associated with coeliac disease. ${ }^{33}$

We also provided questions regarding the key motivation for DS. When viewed geographically in regions with more than 15 respondents, participants from Asia and North America cited general health as a key reason for dietary supplementation (Table 3). The United States are leaders in the manufacturing and distribution of DS, so this is in line with previous research. 
While not statistically significant, it is novel to note that large percentages of respondents felt that DS helped prevent injuries. This could represent a gap in dancers' knowledge of not only the true benefits of certain supplements, but also the inherent dangers when ingesting substances that could have adverse effects than those intended. Interestingly, although not statistically significant, benefits of DS were viewed differently in males and females perceiving the benefits as a means to maintain good health (81\% vs $79 \%)$, to boost the immune system ( $62 \%$ vs $54 \%$ ), and for muscle gain or weight gain ( $25 \%$ vs 4\%). Males also perceived that supplementation improved performance to a greater extent than females, citing the benefits as energy improvement (60\%), performance enhancement (48\%), and reduction in fatigue (60\%). Female respondents perceived benefits focused on compensation for an inadequate $\operatorname{diet}(24 \%)$, as a weight or fat loss mechanism (14\%), and to feel better (28\%).

\section{Information Source for Supplements}

The majority of dancers reported DS use was influenced by friends and colleagues (79\%), price (38\%), brand (37\%), or if DS were "on sale" (14\%). Dance teachers were more influential than doctors or health care professionals, followed by dieticians or nutritionists-11\%, $6 \%$, and $2 \%$, respectively-which would indicate internationally a lack of access or a reticence to seek information from medical and allied health professionals. Thus, evidence-based information may not be a factor in decisions to supplement. Instead decisions may be based on perceptions of benefit from peers and colleagues, representing an area for improvement in dissemination of sound scientifically researched DS information.

No comprehensive dietary evaluation of the participants was undertaken for this study, and therefore the nutritional health of this cohort is not known. Previous research studies in pre- and professional female dancers have reported nutrient deficiency and inadequate caloric intake. ${ }^{34,35}$ However, given the diversity in age, gender, culture, and dance genres of this cohort, we cannot make such generalizations. It is of importance to note that while there are many claims regarding positive outcomes of DS, there is currently no conclusive evidence that DS enhances physiological health parameters in healthy individuals who eat a well-balanced diet. ${ }^{36}$ Conversely, adverse side effects are probable if supplements are taken in large amounts over a longer period. ${ }^{37}$

\section{Knowledge of Supplements}

Knowledge may be an important factor in the decision to supplement or not. It has been suggested that for many dancers the main information source by which to acquire knowledge is through popular culture and not via dieticians, nutritionists, or health-care professionals. ${ }^{14,38}$ Of the participants who answered "no" to taking supplements,
$29 \%$ thought there could be health risks. Respondents who took supplements were more likely to believe that dancing increased the need for supplements (21\%). Seventy-six percent of those taking supplements wanted more information about DS, while only $24 \%$ of those not taking DS thought it necessary to have more information.

One limitation for this study was the international demographic distribution that made it impracticable to do a follow-up interviews for more qualitative data on brand type and quality of supplements used. Future research in this area needs to consider supplement use longitudinally, for example over a full company season or during a 2-year school period. This could provide more data on patterns and trends. Practically, the findings of this study could be used to enable dietetic and nutrition professionals, dance scientists, and physicians working with dancers to provide advice in three areas: firstly, to target common misconceptions held by students, dancers, and educational and artistic professionals on DS; secondly, to provide more accurate and up-to-date information on the limitations as well as the potential benefits of some supplements for certain individuals; and finally, to implement educational programs, in alliance with allied and health professionals across countries, for more applied knowledge lectures and workshops on nutrition.

\section{CONCLUSION}

In summary, we established that DS use was prevalent in this cohort. Both male and females used a variety of supplements, with females ingesting more multivitamins and caffeine than men, and not all females ingesting calcium or calcium substitutes for bone health. In terms of motivation for DS use, a large majority ingested supplements for general health, while more males perceived DS as a means to improve performance. It is concerning that dancers' sources of information on DS may be unreliable. Elite dancers would no doubt benefit from individual consultations with health care professionals knowledgeable in DS use in dancers. Given the current popularity of supplements across nations, it is unlikely that the use of DS by dancers and the general population will significantly diminish in the foreseeable future. Therefore, science and medical professionals such as physicians, dietitians, and exercise physiologists need to be conversant in the latest evidence-based information on DS research to promote themselves as credible information sources amongst dance populations. This study's findings will be useful for dietitians, medical professionals, and the dance science community at large in the development of the most effective means to educate dance students and professionals about DS practices and related concerns.

\section{REFERENCES}

1. Dietary Supplement Health and Education Act of 1994. U.S. Food and Drug Administration, 1994. Available at: http:// 
www.fda.gov / RegulatoryInformation / Legislation / FederalFoodDrugandCosmeticActFDCAct/SignificantAmendments totheFDCAct/ucm 148003.htm.

2. The use of substances with a nutritional or physiological effect other than vitamins and minerals in food supplements. DG, Sanco European, Advisory Services; European Commission; 2007. Available at: http://ec.europa.eu/food/food/labelling nutrition/supplements/index_en.htm.

3. National Center for Health Statistics. 2005-2006 National Health and Nutrition Examination Survey (NHANES). NCHS, updated 12 June 2009. Available at: http://www.cdc.gov/ nchs/nhanes/nhanes2005-2006/nhanes05_06.htm. Accessed 30 June 2009.

4. Consumer consumption of vitamin and mineral food supplements. Food Standards Agency, 2008. Available at: http:// www.foodbase.org.uk / / admintools/reportdocuments / 472-1841_viminsupconsumer.pdf.

5. Heikkinen A, Alaranta A, Helenius I, Vasankari T. Dietary supplementation habits and perceptions of supplement use among elite Finnish athletes. Int J Sport Nutr Exerc Metab. 2011; 21(4): 271-279.

6. Sobal J, Marquart LF. Vitamin/mineral supplement use among athletes: a review of the literature. Int J Sport Nutr. 1994; 4(4):320-334.

7. Diehl K, Thiel A, Zipfel S, et al. Elite adolescent athletes' use of dietary supplements: characteristics, opinions, and sources of supply and information. Int J Sport Nutr Exerc Metab. (2012); 22(3):165-174.

8. Jeukendrup A, Cronin L. Nutrition and elite young athletes. Med Sport Sci. 2011; 56:47-58.

9. Sato A, Kamei A, Kamihigashi E, et al. Use of supplements by young elite Japanese athletes participating in the 2010 youth Olympic games in Singapore. Clin J Sport Med. 2012; 22(5):418423.

10. Burckhardt P, Wynn E, Krieg MA, et al. The effects of nutrition, puberty and dancing on bone density in adolescent ballet dancers. J Dance Med Sci. 2011; 15(2):51-60.

11. Laws H. Fit to Dance2: Report of the Second National Inquiry into Dancers' Health and Injury in the UK. London: Dance UK; 2005.

12. Huang SH, Johnson K, Pipe AL. The use of dietary supplements and medications by Canadian athletes at the Atlanta and Sydney Olympic Games. Clin J Sport Med. 2006; 16(1):27-33.

13. Burke LM, Castell LM, Stear SJ. BJSM reviews: A to Z of supplements: dietary supplements, sports nutrition foods and ergogenic aids for health and performance, Pt 1. Br J Sports Med. 2009; 43(10):728-729.

14. Stensland SH, Sobal J. Dietary practices of ballet, jazz, and modern dancers. J Am Diet Assoc. 1992; 92(3):319-324.

15. Ruxton CHS. The impact of caffeine on mood, cognitive function, performance and hydration: a review of benefits and risks. Nutr Bull. 2008; 33(1):15-25.

16. Woolf K, Bidwell WK, Carlson AG. The effect of caffeine as an ergogenic aid in anaerobic exercise. Int J Sport Nutr Exerc Metab. 2008; 18(4):412-429.

17. Massey LK, Wise KJ. The effect of dietary caffeine on urinary excretion of calcium, magnesium, sodium and potassium in healthy young females. Nutr Res. 1984; 4(1):43-50.

18. Robertson D, Frolich JC, Carr RK, et al. Effects of caffeine on plasma renin activity, catecholamines and blood pressure. $\mathrm{N}$ Engl J Med. 1978; 298(4):181-186.

19. Armstrong LE, Casa DJ, Maresh CM, Ganio MS. Caffeine, fluid-electrolyte balance, temperature regulation, and exerciseheat tolerance. Exerc Sport Sci Rev. 2007; 35(3):135-140.
20. Bishop D. Dietary supplements and team-sport performance. Sports Med. 2010; 40(12):995-1017.

21. Ringham R, Klump K, Kaye W, et al. Eating disorder symptomatology among ballet dancers. Int J Eat Disord. 2006; 39(6):503508.

22. Westerterp-Plantenga MS, Lejeune MPGM, Kovacs EMR. Body weight loss and weight maintenance in relation to habitual caffeine intake and green tea supplementation. Obes Res. 2005; 13(7):1195-1204.

23. Mero A. Leucine supplementation and intensive training. Sports Med. 1999; 27(6):347-358.

24. Mujika I, Padilla S. Creatine supplementation as an ergogenic aid for sports performance in highly trained athletes: a critical review. Int J Sports Med. 1997; 18(7):491-496.

25. Triplett NT, Stone MH, Adams C, et al. Effects of aspartic acid salts on fatigue parameters during weight-training exercise and recovery. J Appl Sports Sci Res. 1990;4(4):141-147.

26. Carr AJ, Hopkins WG, Gore CJ. Effects of acute alkalosis and acidosis on performance: a meta-analysis. Sports Med. 2011; 41(10):801-814.

27. Matson LG, Tran ZV. Effects of sodium bicarbonate ingestion on anaerobic performance: a meta-analytic review. Int J Sport Nutr. 1993; 3(1):2-28.

28. Wyon MA, Twitchett E, Angioi M, et al. Time motion and video analysis of classical ballet and contemporary dance performance. Int J Sports Med. 2011; 32(11):851-855.

29. Frusztajer NT, Dhuper S, Warren MP, et al. Nutrition and the incidence of stress fractures in ballet dancers. Am J Clin Nutr. 1990; 51(5):779-783.

30. Culnane C, Deutsch D. Dancer disordered eating: comparison of disordered eating behavior and nutritional status among female dancers. J Dance Med Sci. 1998; 2(3):95-100.

31. Wolman R, Wyon MA, Koutedakis Y, et al. Vitamin D status in professional ballet dancers: winter vs. summer. J Sci Med Sport. 2013; 16(5):388-391.

32. Hunt JR, Roughead ZK. Adaptation of iron absorption in men consuming diets with high or low iron bioavailability. Am J Clin Nutr. 2000; 71(1):94-102.

33. Zoller H, Vogel W. Iron supplementation in athletes-first do no harm. Nutrition. 2004; 20(7-8):615-619.

34. Doyle-Lucas AF, Akers JD, Davy BM. Energetic efficiency, menstrual irregularity, and bone mineral density in elite professional female ballet dancers. J Dance Med Sci. 2010; 14(4):146-154.

35. Warren MP, Brooks-Gunn J, Fox RP, et al. Lack of bone accretion and amenorrhea: evidence for a relative osteopenia in weight-bearing bones. J Clin Endocrinol Metab. 1991; 72(4):847853.

36. Joint Position Statement: nutrition and athletic performance: American College of Sports Medicine, American Dietetic Association, and Dietitians of Canada. Med Sci Sports Exerc. 2000; 32(12):2130-2145.

37. Schwenk TL, Costley CD. When food becomes a drug: nonanabolic nutritional supplement use in athletes. Am J Sports Med. 2002; 30(6):907-916.

38. Koutedakis Y, Sharp NC. The Fit and Healthy Dancer. West Sussex: John Wiley \& Sons Ltd; 1999.

Appendix 1 appears in the online version of this paper, available at www.sciandmed.com/mppa (see December 2014 issue, vol 29, no 4). 


\section{APPENDIX 1. Dietary Supplementation Questions in Dancers Survey}

1. I consent to participating in the study below

O Yes

O No

2. Which category below includes your age?

O 17

O $18-20$

O $21-29$

O $30-39$

O $40-49$

O $50-59$

O $60-69$

3. You are currently a ...?

O Recreational dance student (local school or dance club)

O Style/ ballroom dance academy

O Pre-professional dance student in university dance department

O Pre-professional dance student(dance academy, conservatory or school)

O Professional dancer (classical)

O Professional dancer (contemporary)

O Professional dancer (hip-hop/urban/street)

O Professional dancer (style/ballroom)

O Professional dancer (world dance)

O Professional dancer (musical)

O Dancing/performing choreographer

O Dancer/entertainer

O Dance teacher

O Other (please specify)

\section{Educational History}

4. You have been training as a student for?

O $0-3$ years

O 3-5 years

O 5-10 years

O 10 or more years

\section{Professional History}

5. How many years have you been dancing professionally?

O $0-3$ years

O 3-5 years

O 5-10 years

O $10-15$ years

O 15-20 years

O 20 or more years

6. You are currently a ....

O Full-time company member

O Part time company member

O Freelancer

O Self-employed

Other (please specify)

7. What is your height? (in centimetres or inches)

8. What is your current weight? (in kilograms or pounds)

9. Do you take nutritional supplements?

O Yes

O No

[Question \#9 above contained question logic that would allow respondents to continue with questions on supplementation or be forwarded to questions on attitude.] 


\section{Energy Supplements}

10. How often do you ingest the following?

Energy drinks (e.g., Gatorade, Lucozade Sport, Red Bull)

\begin{tabular}{cccc} 
Never & $1-2$ days/wk & $3-4$ days/wk & Every day \\
\hline 0 & 0 & 0 & 0 \\
0 & 0 & 0 & 0 \\
0 & 0 & 0 & 0 \\
0 & 0 & 0 & 0 \\
0 & 0 & 0 & 0
\end{tabular}

Calorie replacements (e.g., Recovery mix, recovery bars, energy bars, Slim-Fast)

MCT oils (medium chain triglyceride/ coconut oil)

Pyruvate

Caffeine

\section{Vitamin and Mineral Supplements}

11. How often do you ingest the following? Please add single supplements that you take IN ADDITION to multivitamin and/or multivitamin multimineral supplements.

Multivitamin

Glucosamine/chondroitin

Vitamin E

Vitamin C

Beta-carotene

Folic acid

B 12

Niacin

B-complex vitamins

Vitamin D

Vitamin A

Multivitamin with minerals

Iron

Calcium

Phosphorous

Zinc

Potassium

Selenium

Copper

Magnesium

Cobalt

\begin{tabular}{ccccc} 
Never & $\begin{array}{c}1-2 \\
\text { days/wk }\end{array}$ & $\begin{array}{c}3-4 \\
\text { days/wk }\end{array}$ & $\begin{array}{c}\text { Every } \\
\text { day }\end{array}$ & $\begin{array}{c}\text { I have never } \\
\text { heard of this } \\
\text { supplement }\end{array}$ \\
\hline 0 & 0 & 0 & 0 & 0 \\
0 & 0 & 0 & 0 & 0 \\
0 & 0 & 0 & 0 & 0 \\
0 & 0 & 0 & 0 & 0 \\
0 & 0 & 0 & 0 & 0 \\
0 & 0 & 0 & 0 & 0 \\
0 & 0 & 0 & 0 & 0 \\
0 & 0 & 0 & 0 & 0 \\
0 & 0 & 0 & 0 & 0 \\
0 & 0 & 0 & 0 & 0 \\
0 & 0 & 0 & 0 & 0 \\
0 & 0 & 0 & 0 & 0 \\
0 & 0 & 0 & 0 & 0 \\
0 & 0 & 0 & 0 & 0 \\
0 & 0 & 0 & 0 & 0 \\
0 & 0 & 0 & 0 & 0 \\
0 & 0 & 0 & 0 & 0 \\
0 & 0 & 0 & 0 & 0 \\
0 & 0 & 0 & 0 & 0 \\
0 & 0 & 0 & 0 & 0 \\
0 & 0 & 0 & 0 & 0
\end{tabular}

12. How often do you ingest the following?

Amino acids

Arginine

Aspartic acid

Branched chain amino acids (isoleucine, leucine, valine)

Beta-alanine

Creatine

Omega $3 / 6$ or 9 fish oils

Glutamine

$\mathrm{HMB}$

Weight gain powders

Soy protein and isoflavones

Casein protein

Egg protein

Rice protein

Pea protein

Hemp protein

Whey protein

Sodium bicarbonate

Chromium picolinate

\begin{tabular}{ccccc} 
Never & $\begin{array}{c}1-2 \\
\text { days/wk }\end{array}$ & $\begin{array}{c}3-4 \\
\text { days/wk }\end{array}$ & $\begin{array}{c}\text { Every } \\
\text { day }\end{array}$ & $\begin{array}{c}\text { I have never } \\
\text { heard of this } \\
\text { supplement }\end{array}$ \\
\hline 0 & 0 & 0 & 0 & 0 \\
0 & 0 & 0 & 0 & 0 \\
0 & 0 & 0 & 0 & 0 \\
0 & 0 & 0 & 0 & 0 \\
0 & 0 & 0 & 0 & 0 \\
0 & 0 & 0 & 0 & 0 \\
0 & 0 & 0 & 0 & 0 \\
0 & 0 & 0 & 0 & 0 \\
0 & 0 & 0 & 0 & 0 \\
0 & 0 & 0 & 0 & 0 \\
0 & 0 & 0 & 0 & 0 \\
0 & 0 & 0 & 0 & 0 \\
0 & 0 & 0 & 0 & 0 \\
0 & 0 & 0 & 0 & 0 \\
0 & 0 & 0 & 0 & 0 \\
0 & 0 & 0 & 0 & 0 \\
0 & 0 & 0 & 0 & 0 \\
0 & 0 & 0 & 0 & 0 \\
0 & 0 & 0 & 0 & 0
\end{tabular}


13. Why do you feel you need to take the nutritional supplements? (check all that apply)

O Maintain good health

O Its simply my daily routine

O Boost Immunity

O Were recommended by colleagues

O Were recommended by teachers/choreographers

O Improve energy

O Improve performance

O Reduce fatigue

O Inadequate diet

O Improve speed/agility

O Improve strength / power

O Weight gain/muscle gain

O Able to train longer/endurance

O Speed up my recovery (after injury)

O Weight loss/fat loss

O Makes me feel better

O Increase energy levels

O Prevent injury and illness

O Increase my ability to cope with pain.

O Improve my concentration

O Help me to relax

Other (please specify)

14. When ingesting your dietary supplements, how well do you follow the recommendations on the labels?

O Extremely well

O Very well

O Moderately well

O Slightly well

O Not at all well

15. How would you assess your knowledge of dietary supplements?

O Extremely knowledgeable

O Very knowledgeable

O Moderately knowledgeable

O Slightly knowledgeable

O Not at all knowledgeable

16. Where do you purchase your dietary supplements?

O Sport shops

O Doctor/physician

O Mail order

O Health/whole food store

O Teacher

O Internet

O Other dancers

O Fitness centre

O Supermarket

O Pharmacy

O Acquaintance

Other (please specify)

17. What influences your decision when selecting your supplements?

O Advertising claims

O Price

O Recommendations (by friends, dance colleagues etc.)

O "On sale"

O Brand

O Other (please specify) 
18. How would you rate the following?

Dietary supplementation is associated with health risks

Dietary supplements enhance performance

Dancing increases the need for dietary supplementation

Supplements are not needed with a balanced diet

\begin{tabular}{ccccc}
$\begin{array}{c}\text { Totally } \\
\text { agree }\end{array}$ & $\begin{array}{c}\text { Somewhat } \\
\text { agree }\end{array}$ & Unsure & $\begin{array}{c}\text { Somewhat } \\
\text { disagree }\end{array}$ & $\begin{array}{c}\text { Totally } \\
\text { disagree }\end{array}$ \\
\hline 0 & 0 & 0 & 0 & 0 \\
0 & 0 & 0 & 0 & 0 \\
0 & 0 & 0 & 0 & 0 \\
0 & 0 & 0 & 0 & 0
\end{tabular}

19. Would like to get more advice on dietary supplement benefits for dancers?

O Yes

O No

\section{Demographic Information}

20. Which country are you originally from?

21. In which country do you currently live?

22. Are you male or female?

O Male

O Female

The End

Thank you for your time and energy to complete this questionnaire.

Once you click the "Done" button, the survey response will be submitted. 